\title{
EFEKTIFITAS EKSTRAK DAUN SUKUN (Artocarpus altilis) TERHADAP PERTUMBUHAN BAKTERI Shigella $s p$
}

\author{
Anita $^{1)}$, Muh. Rifo rianto ${ }^{1)}$, Supardi ${ }^{1)}$ \\ 1)Akademi Analis Kesehatan Muhammadiyah Makassar \\ Alamat Korespondensi: nita_uh@yahoo.co.id
}

\begin{abstract}
ABSTRAK
Penelitian ini dilatar belakangi oleh keadaan bakteri yang semakin lama samakin banyak mengalami resisten terhadap antibiotik moderen. Daun sukun (Artocarpus altilis) memiliki beberapa senyawa metabolik sekunder yang dapat menghambat pertumbuhan bakteri dan juga lebih aman untuk dikonsumsi. Tujuan penelitian ini untuk mengetahui kemampuan ekstrak daun sukun dalam menghambat pertumbuhan bakteri Shigella sp. Jenis penelitian ini bersifat eksperimental, menggunakan metode difusi agar. Sampel yang digunakan yaitu Daun sukun (Artocarpus altilis) sebanyak 300 gram yang diekstrak kemudian dibuat konsentrasi 25\%, 45\% dan $75 \%$. Hasil dari penelitian ini pada konsentrasi $25 \%$ rata-rata zona hambat yang diperoleh yaitu $7.5 \mathrm{~mm}$, pada konsentrasi $45 \%$ rata-rata zona hambat yang diperoleh yaitu $10.7 \mathrm{~mm}$, pada konsentrasi $75 \%$ didapatkan rata-rata zona hambat yaitu $13.2 \mathrm{~mm}$. Uji daya hambat yang dilakukan pada penelitian ini menunjukkan bahwa ekstrak daun sukun pada konsentrasi 25\%, 45\%, dan 75\% mampu menghambat pertumbuhan bakteri Shigella sp.
\end{abstract}

Kata kunci: Daun sukun (Artocarpus altilis), Daya hambat, Shigella sp.

\section{PENDAHULUAN}

Indonesia termasuk negara di wilayah bagian Asia Pasifik yang mempunyai hutan tropis terluas ketiga di dunia setelah wilayah dibagian Amerika Selatan dan Afrika. Hal ini membuat Indonesia kaya akan sumber daya hayati, salah satu diantaranya adalah tanaman yang dapat berkhasiat sebagai obat. Hutan tropis Indonesia merupakan tempat tumbuh bagi 80 persen tanaman obat yang ada di dunia yang terdiri dari 28.000 spesies tanaman, 1000 spesies diantaranya sudah digunakan sebagai tanaman obat (Aprilina, 2013).

Penggunaan tanaman sebagai obat telah sejak lama digunakan sebagai alternatif pengobatan dari berbagai masalah penyakit. World Health Organization (WHO) juga telah merekomendasikan penggunaan obat tradisional termasuk herbal dalam pemeliharaan kesehatan masyarakat, pencegahan dan pengobatan penyakit terutama untuk penyakit kronis, degeneratif dan kanker. Salah satu tanaman herbal yang digunakan sebagai alternatif pengobatan saat ini yaitu (Artocarpus altilis) (Aprilina, 2013).

Sukun (Atrocarpus altilis) merupakan tanaman yang keberadaannya sangat banyak di Indonesia namun pemanfaatannya masih kurang optimal. Manfaat tanaman sukun dapat diperoleh dari semua bagiannya mulai dari akar, batang, buah, hingga daunnya (Mardiana, 2012).

Daun sukun dapat dimanfaatkan sebagai anti mikroba, hal ini pernah diteliti sebelmunya. Dalam penelitian tersebut dikatakan bahwa aktivitas ekstrak etanol daun sukun (Artocarpus altilis) terbukti sebanding dengan antibiotik tetrasiklin dan ketokenazol terhadap bakteri Escherichia coli dan jamur Candida albicans dan Microsporum gypseum. Skrining fitokimia menunjukan adanya golongan senyawa flavonoid, tanin, saponin, steroid dan polifenol yang dapat berfungsi sebagai antibakteri (Hermanto, 2012). 


\section{METODE PENELITIAN \\ Alat dan Bahan}

Alat yang digunakan adalah timbangan digital, gelas kimia, gelas ukur, rotavavor, labu erlenmeyer, cawan petri, kapas swab steril, aluminium foil, batang pengaduk, corong, pemanas listrik, pencadang, pinset dan sendok tanduk.

Bahan yang digunakan adalah aquadest, etanol $70 \%$, daun sukun, media NA, media MHA, $\mathrm{NaCl}$ dan disk tetrasiklin.

\section{Prosedur Kerja \\ Pembuatan ekstrak daun sukun dengan metode maserasi}

Daun sukun yang masih segar dicuci bersih, diiris kecil-kecil kemudian dikeringkan diudara terbuka dan terkena sinar matahari selama kurang lebih 2 hari sampai kering sempurna. Setelah itu, daun sukun kering ditimbang sebanyak 300 gram kemudian dimasukkan ke dalam wadah lalu direndam dengan cairan etanol $70 \%$ sebanyak \pm 3 liter. Perendaman dibiarkan selama $7 \quad$ x 24 jam pada temperatur kamar dan terlindung dari cahaya sambil diaduk sekali-kali, kemudian disaring. Ekstrak etanol cair yang diperoleh kemudian dikumpulkan, diuapkan dengan menggunakan rotavapor, kemudian diangin-anginkan ditempat yang terlindung dari cahaya matahari langsung sampai diperoleh ekstrak kental daun sukun.

Prosedur pengujian daya hambat ekstrak daun sukun dengan metode difusi agar berlapis

Media MHA (Muller Hinton Agar) steril bersuhu $40^{\circ} \mathrm{C}-45^{\circ} \mathrm{C}$ dituang secara aseptis ke dalam cawan petri sebanyak 10 $\mathrm{ml}$ sebagai (base layer), media dibiarkan memadat. Selanjutnya, suspensi bakteri diinokulasikan lalu dihomogenkan dengan $10 \mathrm{ml}$ media MHA yang telah dituang di atas base layer, lapisan ini merupakan seed layer. Biarkan media setengah memadat.

Setelah itu 4 buah pencadang diletakkan secara aseptis dengan pinset steril pada permukaan medium dengan jarak pencadang satu dengan yang lain 2$3 \mathrm{~cm}$ dari pinggir cawan petri, dan dibiarkan pada suhu kamar.

Masing-masing pencadang diisi ekstrak daun sukun dengan masingmasing konsentrasi, yaitu 25\%, 45\%, $75 \%$, dan juga akuades steril (kontrol negatif) ditempelkan pada bidang kosong pada media MHA disk tetrasiklin (kontrol positif).

Selanjutnya, diinkubasi selama $1 \times 24$ jam pada suhu $37^{\circ} \mathrm{C}$. Setelah masa inkubasi diukur diameter zona hambatan pertumbuhan bakteri di sekeliling pencadang dengan menggunakan jangka sorong. Pengujian diulang sebanyak 3 kali.

\section{HASIL DAN PEMBAHASAN}

Dari penelitian eksperimental yang dilaksanakan di Rumah Sakit Pendidikan Unhas Makassar (RSP) ini diperoleh hasil penelitian pada tabel 1 berikut.

Tabel 1. Dimater Zona Hambatan Shigella sp oleh Daun Sukun Konsentrasi $25 \%, 45 \%, 75 \%$

\begin{tabular}{|c|c|}
\hline \multicolumn{2}{|c|}{ Konsentrasi $25 \%, 45 \%, 75 \%$} \\
\hline Konsentrasi Daun Sukun & $\begin{array}{c}\text { Rata-rata } \\
\text { Diamter Zona } \\
\text { Hambatan } \\
(\mathrm{mm})\end{array}$ \\
\hline $25 \%$ & 7.5 \\
\hline $45 \%$ & 10.7 \\
\hline $75 \%$ & 13.2 \\
\hline Dari & penelitian \\
\hline
\end{tabular}
menggunakan ekstrak daun sukun dengan 3 konsentrasi yaitu 25\%, 45\%, 75\%, menunjukkan bahwa ekstrak daun sukun (Artocarpus altilis) mampu menghambat pertumbuhan bakteri Shigella sp dengan luas rata-rata zona hambat yang terbentuk pada konsentrasi $25 \%$ sebesar $7.5 \mathrm{~mm}$, pada konsentrasi $45 \%$ sebesar $10.7 \mathrm{~mm}$, dan pada konsentrasi $75 \%$ sebesar 13.2 $\mathrm{mm}$. 


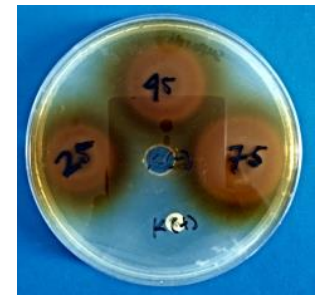

Gambar 1.Hasil Uji Daya Hambat Ekstrak Daun Suku Konsentrasi 25\%, $45 \%, 75 \%, \mathrm{~K}(+)$ tetracycline, K (-) aquadest steril.

\section{PEMBAHASAN}

Penelitian uji daya hambat ekstrak daun sukun pada bakteri Shigella $s p$ dilakukan secara eksperimen dengan meggunakan metode difusi agar berlapis yang bertujuan untuk mengetahui kemampuan ekstrak daun sukun dalam menghambat pertumbuhan bakteri yang dijadikan ukuran.

Sampel pada penelitian ini menggunakan ekstrak daun sukun konsentasi 25\%, 45\%, dan 75\%. Daun sukun (Artocarpus altilis) mengandung beberapa senyawa metabolit sekunder yang dapat menghambat pertumbuhan bakteri, utamanya flavonoid. Sedangkan bakteri yang diuji adalah Shigella $s p$.

Kontrol positif yang digunakan dalam penelitian ini adalah disk tetracycline $30 \mathrm{bpj}$. Hal ini didasarkan bahwa antibiotik ini diketahui dapat menghambat pertumbuhan sebagian besar bakteri Gram positif maupun Gram negatif. Kontol positif juga digunakan untuk menguji apakah kultur bakteri yang digunakan dalam penelitian masih layak untuk diuji atau tidak. Sedangkan kontrol negatif yang digunakan adalah aquades steril.

Hasil penelitian yang telah dilakukan menunjukkan adanya zona hambat yang terbentuk. Pengujian pertama kosentrasi $25 \%$ diperoleh hasil diameter zona hambat $6.5 \mathrm{~mm}$. Pengujian kedua diperoleh hasil diameter zona hambat $8 \mathrm{~mm}$. Dan pada pengujian ketiga diperoleh hasil rata-rata $8 \mathrm{~mm}$. Selanjutnya pada ketiga hasil rata-rata zona hambat tersebut dirata-ratakan kembali dan diperoleh hasil zona hambat $7.5 \mathrm{~mm}$ untuk konsentrasi $25 \%$.
Konsentrasi kedua yaitu $45 \%$ yang diperoleh hasil pengukuran $9.5 \mathrm{~mm}$ pada pengujian pertama, untuk pengujian kedua diperoleh hasil $10.5 \mathrm{~mm}$, dan pada pengujian ketiga diperoleh hasil $12 \mathrm{~mm}$. Selanjutnya pada ketiga hasil rata-rata zona hambat tersebut dirata-ratakan kembali dan diperoleh hasil zona hambat $10.7 \mathrm{~mm}$ untuk konsentrasi $45 \%$.

Kosentrasi ketiga yaitu $75 \%$ yang diperoleh hasil pengukuran zona hambat 9 $\mathrm{mm}$ pada pengujian pertama, untuk pengujian kedua diperoleh hasil $15.5 \mathrm{~mm}$, dan pada pengujian ketiga diperoleh hasil $15 \mathrm{~mm}$. Selanjutnya pada ketiga hasil rata-rata zona hambat tersebut dirataratakan kembali dan diperoleh hasil zona hambat $13.2 \mathrm{~mm}$ untuk konsentrasi $75 \%$.

Lebih besarnya zona hambat yang terbentuk pada konsentrasi $75 \%$ dibandingkan konsentrasi $25 \%$ dan $45 \%$ (mm) menunjukkan bahwa daya hambat ekstrak daun sukun berbanding lurus dengan pertumbuhan bakteri Shigella $s p$, maka semakin tinggi konsentrasi ekstrak semakin besar juga zona hambat yang akan terbentuk.

Hasil penelitian ini membuktikan bahwa ekstrak daun sukun (Artocarpus altilis) dapat menghambat pertumbuhan bakteri gram negatif dikarenakan dalam daun sukun terdapat beberapa senyawa metabolik skunder yang dapat menghambat pertumbuhan bakteri. Penelitian terhadap uji daya hambat ekstrak daun sukun (Artocarpus altilis) juga pernah dilakukan sebelumnya oleh Sucy lestari di Fakultas Kedokteran Universitas Syiah Kuala Darussalam Banda Aceh (2014). Pada penelitian tersebut menggunakan ekstrak daun sukun dengan konsentrasi 25\%, 50\%, $75 \%$ dan $100 \%$ dengan bakteri uji Methicillin-Resistant Staphylococcus aureus. Hasil penelitian tersebut juga menunjukkan hasil yang sama yang menunjukkan bahwa ekstrak daun sukun mampu menghambat bakteri MethicillinResistant 
Staphylococcus aureus dengan zona hambat pada konsentrasi $25 \%$ yaitu 8.0 $\mathrm{mm}$, pada konsentrasi $50 \%$ yaitu $9.0 \mathrm{~mm}$, pada konsentrasi $75 \%$ yaitu $10.25 \mathrm{~mm}$ dan pada konsentrasi $100 \%$ yaitu 11.5 $\mathrm{mm}$.

\section{KESIMPULAN}

Berdasarkan hasil penelitian yang telah dilakukan didapatkan luas zona hambat yang terbentuk pada konsentrasi $25 \%$ rata-rata $7.5 \mathrm{~mm}$, pada konsetrasi $45 \%$ rata-rata zona hambat yang terbentuk $10.7 \mathrm{~mm}$, dan pada konsentrasi $75 \%$ ratarata zona hambat yang terbentuk 13.2 $\mathrm{mm}$. Dari hasil penelitian tersebut, dapat disimpulkan bahwa ekstrak daun sukun (Artocarpus altilis) dapat menghambat pertumbuhan bakteri Shigella sp.

\section{SARAN}

Untuk peneliti selanjutnya, diharapkan dapat dilakukan penelitian lebih lanjut mengenai uji daya hambat ekstrak daun sukun dengan menggunakan bakteri uji yang lain agar semakin banyak informasi yang dapat diperoleh bagi masyarakat tentang kemampuan daun sukun dalam mengatasi berbagai masalah penyakit.

\section{DAFTAR PUSTAKA}

Ainurrochmah, A. Ratnasari, E. Lisdiana, L. 2013. Efektivitas Ekstrak Daun Binahong (Anredera cordifolia) terhadap Penghambatan Pertumbuhan Bakteri Shigella flexneri dengan Metode Sumuran. Jurnal Mipa (Online).http://ejournal.unesa.ac.id/ index.php/lenterabio/article/view/4 $343 / 6817$.

Aprilina, F. 2013. Profil Penggunaan Obat Tradisional Pada Masyarakat Di Kabupaten Tabalong Kalimantan Selatan Tahun 2013 (Karya Tulis Ilmiah). Surakata: Universitas Muhammadiyah Surakarta.

Bontjura, s. Waworuntu, O. A. Siagian, K. V. 2015. Uji efek antibakteri ekstrak daun leilem (Clerodendrum minahassae l.) terhadap bakteri
Streptococcus mutans. Jurnal Ilmiah Farmasi - UNSRAT. (Online)

Vol.4.No.4(ejournal.unsrat.ac.id/in dex.php/pharmacon/. Diunduh 2 maret 2016).

Fadhli, A. 2015. Disentri Basiler. (Online),http://documents.tips/docu ments/disentri-basiler-fix-00.html.

Ganiswarna .S .G, 2007. Farmakologi dan Terapi. Jakarta: Fakultas Kedokteran UI.

Hatiyati, T., Jekti, D.S.D., Adayani, Y. 2015. Pengaruh Ekstrak Etanol

Daun Jambu Air (Syzygium aqueum) Terhadap Bakteri Isolat Klinis. Jurnal Penelitian Pendidikan Ipa (Online). Vol.1,No.2. Available from:

(http://jurnal.unram.ac.id/index.php /jpp-ipa).

Hermanto, N. (2012). Daun Sukun Si Daun Ajaib Penakluk Aneka Penyakit. Jakarta: PT AgroMedia Pustaka.

Istiqomah, 2013. Perbandingan Metode Ekstraksi Maserasi Dan Sokletasi Terhadap Kadar Piperin Buah Cabe Jawa (Piperis retrofracti fructus), Jakarta: Universitas Islam Negeri Syarif Hidayatullah.

Jawetz, Melnick, Adelberg, 2012. Mikrobiologi Kedokteran. Buku Kedekteran. Jakarta: EGC.

Jiwanjaya, Y. 2014. Bakteri Shigella dysenteriae Penyebab Penyakit Disentri. Available from: http://www.biologiedukasi.com/20 14/ 11/bakteri-shigella-dysenteriaepenyebab. html.

Junanto, T., Sutarno, Supriyadi. 2008. Aktivitas Antimikroba Ekstrak Angsana (Pterocarpus indicus) Terhadap Bacillus subtilis Dan Klebsiella pneumonia. Available from: $\quad \mathrm{http} / / /$ biosains.mipa. uns.ac.id/C/C0502/C050204.pdf.

Ngajow, M., Abidjulu, J., Kamu, V.S. 2013. Pengaruh Antibakteri Ekstrak Kulit Batang Matoa 
(Pometia pinnata) terhadap Bakteri Staphylococcus aureus secara In vitro. Jurnal MIPA UNSRAT (Online). Vol.2,No.128132. Available from: (http://ejournal.unsrat.ac.id/index.p $\mathrm{hp} / \mathrm{jmuo}$ ).

Nuraina. 2015. Uji Aktivitas Antimikroba Ekstrak Daun Garcinia Benthami Pierre Dengan Metode Dilusi. Jakarta: Universitas Islam Negeri Syarif Hidayatullah Jakatra.

Mardiana, Lina 2012. Daun Ajaib Tumpas Penyakit. Jakarta: Penebar Swadaya.

Ramli, S.A.S. 2011. Shigellosis. Available from: https://www.scribd.com/doc /47751221/SHIGELLOSIS.

Retnowati, Y., Bialangi, N., Posangi, N.W. 2011. Pertumbuhan Bakteri Staphylococcus Aureus Pada Media Yang Diekspos Dengan Infus Daun

Sambiloto(Andrographispaniculata) (Online). Available from: https://repository.ung.ac.id/mbuhanBakteri-Staphylococcus-AureusPada-Media-Yang-DieksposDengan-Infus-Daun SambilotoAndrographis-Paniculata.pdf.

Rijayanti, 2014. Uji Aktivitas ZAntibakteri Ekstrak Etanol Daun Mangga Bacang (Mangifera foetida L.) Terhadap Staphylococcus aureus. Available from: http://jurnal.untan.ac.id/index.php/jf k/article/viewFile/6330/ 6509.

Sari, M. 2015. Uji Bakteriologis Dan Resistensi Antibiotik Terhadap Bakteri Escherichia Coli Dan Shigella Sp. Pada Makanan GadoGado Di Kantin Uin Syarif Hidayatullah Jakarta. Available from:http://repository.uinjkt.ac.id/ds pace/bitstream/123456789/29523/1/ Mulia\%20Sari-fkik.pdf.

Sari, E.N. 2015. Shigella. Available from: http://documentslide.com/documnts /shigella-5604356b38e53.html.

Sembel, D. T. $2015 . \quad$ Toksikologi Lingkungan. Yogyakarta: ANDI.

Sri, F. 2016. Pengertian Bakteri Gram Positif dan Negatif. Available from: http://www.sridianti.com/pengertia n-bakteri-gram-positif-dannegatif.html.

Yudho, H. 2015. Tertarik Menanam Bibit Sukun? Ini Caranya (online). Available from: http://www.agroraya.com/bibitsukun. 